\title{
New Strategies for Treatment of Infectious Sepsis
}

\author{
Peter A. Ward* and Fatemeh Fattahi
}

Department of Pathology, University of Michigan Medical School, Ann Arbor, MI,

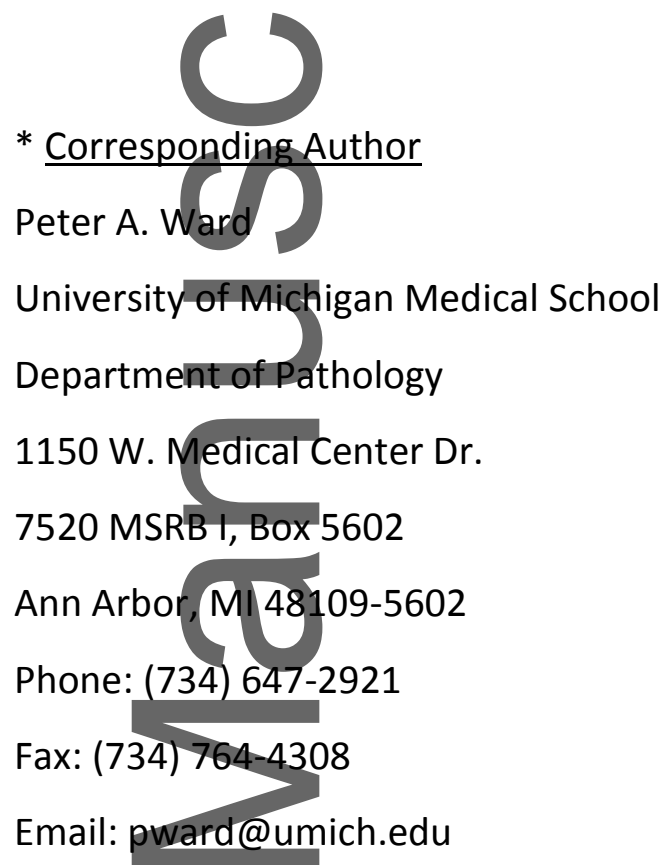

Summary Sentence: New information about infectious sepsis suggests new therapeutic targets that include complement activation products and receptors, histones and the NLRP3 inflammasome

Running Title: Novel Strategies for Treatment of Sepsis

Key Words: Complement, complement receptors, histones, NLRP3 inflammasome.

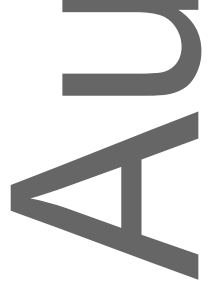

This is the author manuscript accepted for publication and has undergone full peer review but has not been through the copyediting, typesetting, pagination and proofreading process, which may lead to differences between this version and the Version of Record. Please cite this article as doi: 10.1002/JLB.4MIR1118-425R.

This article is protected by copyright. All rights reserved. 


\section{Abbreviations}

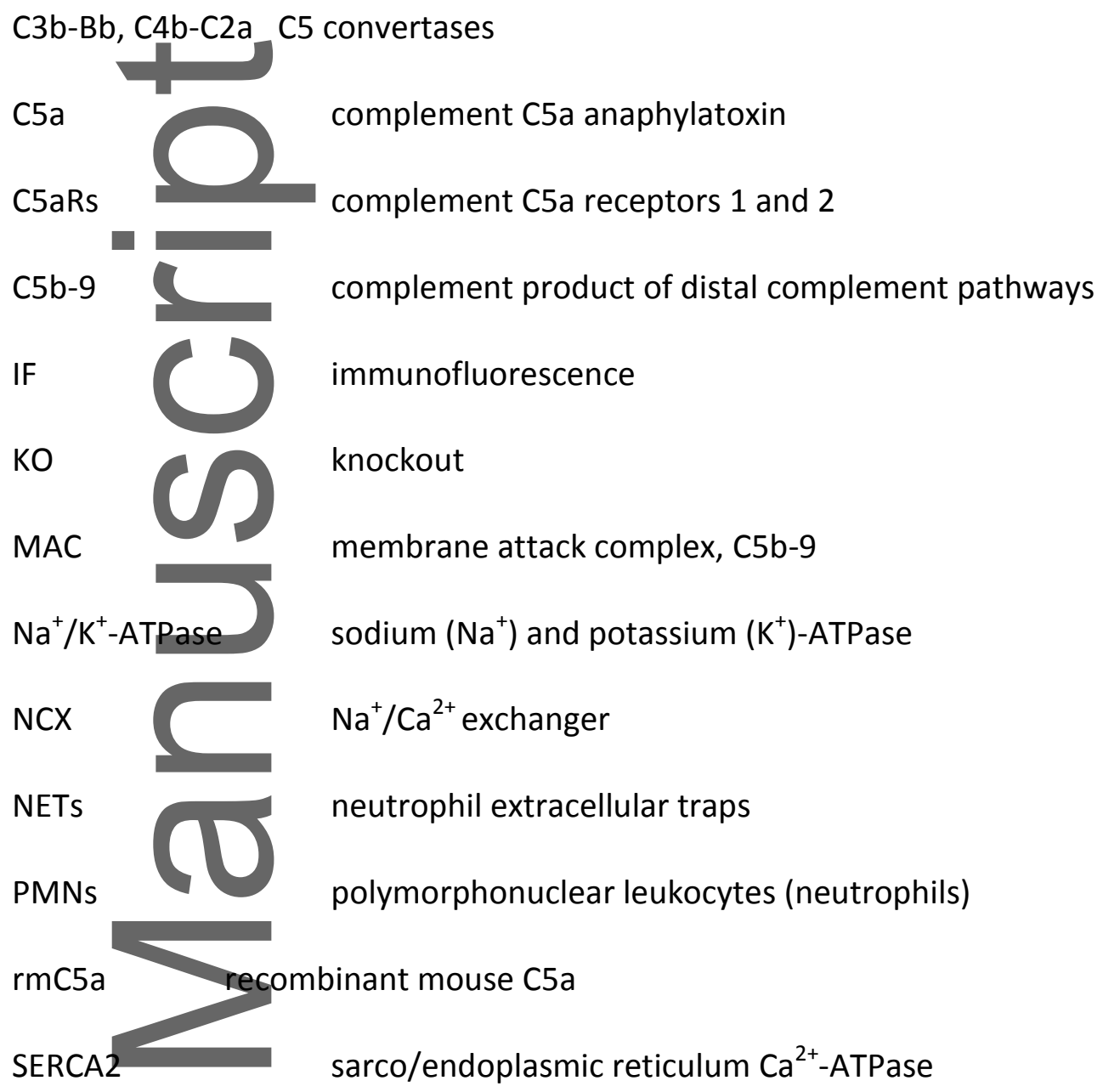

In this Mini-Review, we describe the molecular mechanisms in polymicrobial sepsis that lead to a series of adverse events including activation of inflammatory and prothrombotic pathways, a faulty innate immune system, and multiorgan dysfunction. Complement activation is a well-established feature of sepsis, especially involving generation of $\mathrm{C} 5 \mathrm{a}$ and $\mathrm{C} 5 \mathrm{~b}-9$, along with engagement of relevant receptors for $\mathrm{C} 5 \mathrm{a}$ Activation of neutrophils (PMNs) by C5a leads to extrusion of DNA, forming neutrophil extracellular traps (NETs) which contain myeloperoxidase and oxidases, along with 
extracellular histones. Generation of the distal complement activation product, $\mathrm{C} 5 \mathrm{~b}-\mathrm{9}$ (known as the membrane attack complex, MAC), also occurs in sepsis. C5b-9 activates the in NLRP3 inflammasome, which damages mitochondria, together with appearance in plasma of $\mathrm{IL}-1 \beta$ and $\mathrm{IL}-18$. Histones are strongly proinflammatory as well as being prothrombotic, leading to activation of platelets and development of venous thrombosis. Multiorgan dysfunction is also a feature of sepsis. It is well known that septic cardiomyopathy, which, if severe, can lead to death. This complication in sepsis is linked to reduced levels in cardiomyocytes (CMs) of three critical ATPase proteins. The reductions in these three key proteins are complement- and histone-dependent. Dysfunction of these ATPases is linked to the cardiomyopathy of sepsis. These data suggest novel targets in the setting of sepsis in humans.

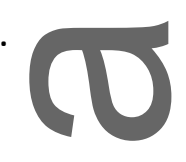

1. Introduction

Infectious sepsis in North America involves more than 500,000 humans annually [1], with a death rate of $\sim 40 \%$ depending on the severity of sepsis [2]. These infections chiefly are triggered by bacteria, but viruses, fungi and protozoa may also cause sepsis [3, 4]. In spite of extensive research in septic animals and humans, there has yet to be a Federal Drug Administration (FDA)-approved drug specifically for treatment of sepsis. Supportive care such as fluid resuscitation, broad spectrum antibiotics delivered early, and safer techniques for mechanical ventilation have improved clinical outcomes in septic patients [5]. This MiniReview describes information gained from the study of polymicrobial sepsis in mice, which is providing new insights into interventions that may pave the way for new strategies for treatment of humans with sepsis. 
It is important to mention the extent to which genomic studies in humans and in mice have influenced our understanding of sepsis. A few years ago, a consortium of investigators compared genomic analysis using blood leukocytes from humans and mice that had experimental sepsis, burn injury and other "inflammatory stresses". The report by Seok et al[6] concluded that "genomic responses in mouse models poorly mimic human inflammatory diseases". This led to many reports in newspapers, suggesting that use of mice was essentially irrelevant for trying to understand human sepsis. In 2015, a group from Japan, using the same database came to an opposite conclusion, that "genomic response in mouse models greatly mimic human inflammatory diseases" [7]. This controversy has, as of 2018, not been resolved and represents a troubling problem, especially since both articles were published in a respected scientific journal (Proceedings of the National Academy of Sciences of USA). As of now, there is no consensus that genomic analysis of mice with sepsis (n) can reliably be extrapolated to humans with sepsis, and this has caused large pharma companies to avoid research investment in the field of sepsis, whether the activity involves mice with polymicrobial sepsis or septic humans. On the other hand, it should be emphasized that the use of septic mice has allowed studies that could not be done in humans with sepsis (such as measurements of regulatory proteins in cardiomyocytes). Septic mice have provided important information on signaling pathways and how these pathways can be manipulated to reduce organ dysfunction in sepsis, at least in mice. Finally, studies show a link between complement product of C5a and adverse outcomes in septic mice and in septic humans. Use of knockout (KO) mice (lacking C5a receptors, C5aRs) have been shown to be protected from adverse events in the heart developing in sepsis $[8,9]$. This emphasizes that certain manipulations can be done in septic mice that add important 
information on how sepsis causes organ dysfunction and might have application in septic humans.

\section{Role of Complement in Polymicrobial Sepsis (Figure 1)}

Polymicrobial sepsis has been frequently used for the study of sepsis in rats and mice, especially sepsis induced by cecal ligation and puncture (CLP), which often closely mimics the clinical picture of humans with sepsis [10-13]. The procedure, originally described nearly 40 years ago [14], has been widely used, in part due to the availability of KO mice. The technique involves a through-and-through puncture of the cecum, with extrusion of small amounts of feces into the peritoneal cavity. The intensity of sepsis can be controlled by the numbers of punctures and the size (gauge) of the needle [15]. "Polymicrobial" refers to the presence of both aerobic and anaerobic bacteria that appear in<smiles>[CH]1CC1</smiles>
the peritoneal cavity and in blood of septic mice [16]. The polymicrobial sepsis model has rarely been used in larger animals or subhuman primates, in part because in such cases an ICU setting would have to be available, requiring animal care around the clock, all of which would result in exceptionally high operating costs. In addition, obtaining institutional approval for use of CLP in subhuman primates would be highly problematic.

Complement activation products and relevant receptors involved in polymicrobial sepsis are described in Figure 1. The onset of sepsis triggers activation of several of the complement pathways, with the "classical" and the "alternative" pathways being activated in polymicrobial sepsis [17]. It remains to be determined what precisely triggers activation of these pathways. The $C 5$ convertase in the classical pathway involves $C 4 b$ and $C 2 a$, while in the alternative pathway $\mathrm{C} 3 \mathrm{~b}$ and $\mathrm{Bb}$ represent the $\mathrm{C} 5$ convertase. In either case, $\mathrm{C} 5 \mathrm{a}$ and 
C5b are generated. It is not clear what triggers complement activation in infectious sepsis involving mice with polymicrobial sepsis or septic humans. It is well established that Gram negative bacteria often activate complement by interaction via the lectin pathway. This features the mannose-binding lectin interacting with carbohydrates on the surfaces of bacteria. Related to the innate immune system, there are many pattern-associated molecular patterns (PAMPs) and damage-associated molecular patterns (DAMPs) that can activate complement. For example, bacterial lipopolysaccharide (LPS) from Gram negative bacteria is a Well-known bacterial product that activates the alternative complement pathway. LPS interacts with TLR2 and TLR4 causing activation of signaling pathways in a variety of cells (Figure 3). Finally, certain Gram positive bacteria (e.g. Staph. aureus) secrete proteins that block complement activation molecules. The third pathway ("lectin" pathway), is sometimes the chief pathway of complement activation in bacterial-induced .

sepsis [17]. Whatever pathway is being triggered, there is appearance of C5a, the powerful anaphylatoxin, which reacts with its receptors (C5aR1 and C5aR2) that are especially prevalent on neutrophils (PMNs) $[18,19]$. A consequence of these events is strong activation of PMNs and, to a lesser extent, macrophages [18, 19]. Activated PMNs release long strands of DNA forming neutrophil extracellular traps (NETs) along with release of histones as well as products of PMN-specific granules (myeloperoxidase, proteases, etc.) [20-22]. Histones $(\mathrm{H} 1, \mathrm{H} 2 \mathrm{~A}, \mathrm{H} 2 \mathrm{~B}, \mathrm{H} 3, \mathrm{H} 4)$ are molecules with potent proinflammatory and prothrombotic activities inducing biological responses [23]. As will be emphasized in Figure 2, extracellular histones play key effector roles in human and mouse sepsis. Histones can cause diffuse vascular and epithelial cell damage and play important roles in multiorgan 
dysfunction that develops in sepsis. Downstream complement activation also results in generation of C5b-9 (membrane attack complex, MAC) (Figure 3).

It is important to emphasize that complement activation via either the classical or the alternative pathway results in generation of $\mathrm{C} 5$ convertase which generates both $\mathrm{C} 5 \mathrm{a}$ and $\mathrm{C} 5 \mathrm{~b}$. C5a reacts with $\mathrm{C} 5 \mathrm{aRs}$ on PMNs, causing production of NETs, which release histones that have powerful proinflammatory functions. Generation of C5b interacts with C6, C7, C8 and C9 to form C5b-9. This complex is known to activate the NLRP3 inflammasome which results in inflammasome activation, mitochondrial damage and release of $\mathrm{IL}-1 \beta$ and IL-18 which are powerful proinflammatory cytokines. The NLRP3 inflammasome in its precursor mode, exists in a variety of cells (PMNs, macrophages, cardiomyocytes, astrocytes, etc.). Briefly, the inflammasome protocol consists of the "priming" phase in which cells are exposed to LPS $(100 \mathrm{ng} / \mathrm{ml})$ for $4 \mathrm{hr}$ at $37^{\circ} \mathrm{C}$. This results in

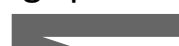
very little release of IL-1 13 . Thereafter, the cells are exposed to $1 \mathrm{mM}$ ATP for $45 \mathrm{~min}$, which serves as an "activator", resulting in very substantial release of IL-1 $[22,23]$. Suresh et al also demonstrated that complement-mediated "bystander" damage, during the phagocytosis of complement-opsonized particles in macrophages, initiates NLRP3 inflammasome activation, resulting in caspase- 1 activation and IL-1 $\beta$ and IL-18 secretion [24]. To an extent, complement-dependent activation or inflammasome activation can cause acute cellular and organ dysfunction via C5a and C $5 b-9$ by the mechanisms described above. Such adverse events can occur whenever complement or inflammasome activation occurs. In this sense, cell damage does not occur in a targeted manner, but in the vicinity of where activation of complement or inflammasome is occurring, such that a variety of cells may be damaged. 
Regarding bacteria and the complement system, it is well established that Gram positive bacteria, such as Staph. aureus, are resistant to effects of complement activation while Gram negative bacteria are sensitive to effects of complement activation. For instance, some Staph. aureus bacteria are resistant to methicillin and may pose a grave danger to individuals. It should also be emphasized that many Gram negative bacteria release LPS which react with $\operatorname{TLRs}(2,3,4,9)$ that in the setting of sepsis may collectively contribute to the adverse events in infectious sepsis [25]. Complement activation products such as $\mathrm{C} 3 \mathrm{~b}$ and $\mathrm{iC} 3 \mathrm{~b}$ promote phagocytosis of bacteria and their intracellular killing by PMNs and macrophages, often via NADPH oxidase and its products, oxygen-derived free radicals $[26,27]$. In addition, as mentioned above, MAC also has cytolytic effects on bacteria via MAC or via the lectin and NLRP3 inflammasome pathways. Bacteria can also activate the lectin pathway of complement, resulting in antibacterial effects described above. It should also be pointed out that certain Gram positive bacteria (such as Staph. aureus) release peptides that block complement activation or complement activation products [28].

The issue of whether complement complexes such as C5b-7 or C5b-8 assert cell damaging activity has by-in-large not been convincingly shown in experimental studies. A recent study by Morgan's group showed that in the absence of C9, sublytic MAC cannot be generated so cannot drive inflammation and apoptosis in human lung epithelial cells as found by studying cytokine production, NLRP3 inflammasome activation, cytosolic $\mathrm{Ca}^{2+}$ increase, mitochondrial dysfunction and cytochrome c release [29]. It should be mentioned that most of the published information related to $\mathrm{C} 5 \mathrm{~b}-7$ and $\mathrm{C} 5 \mathrm{~b}-8$ fails to show damaging effects on mammalian cells. 


\section{Mechanisms of Histone-induced Cell Damage in Sepsis (Figure 2)}

Figure 2 describes our recent work that has defined signaling pathways occurring in Fister onset 2 descr

the heart after onset of CLP-induced sepsis. A major event is activation of PMNs by C5a, resulting in appearance of NETs and extracellular histones. It has been established that histones bind to toll-like receptors (TLRs) in various cell types [30-33], including cardiomyocytes (CMs) [34]. This results in activation of platelets and development of thrombosis. Another major event occurring in the presence of extracellular histones is activation of PMNs and macrophages, causing generation of intracellular oxidants (reactive oxygen species, ROS) in a variety of cells, as well as appearance of proinflammatory peptides (cytokines, chemokines and other factors), all of which cause cell dysfunction and, often, apoptosis, especially in the setting of infectious sepsis [35]. Other damaging features of histones is that they can directly cause cell damage and apoptosis and are very res prothrombotic and proinflammatory [36]. Several studies showed that histones bind to different TLRs (mainly TLR2 and TLR4) and interact with these receptors on various cell types [30-33, 37]. It should be mentioned that depending on the experimental setting and cell lines used, there are additional data about TLR2 or TLR4 being activated by histones. The study by Xu et al showed TLR4, but not TLR2, was the major receptor for a histone-induced cytokine inflammatory response after histone infusion into TLR4 KO mice [30]. The study by Ekaney et al [38] also showed that blocking TLR4 resulted in decreased cellular cytotoxicity on human endothelial cells (as measured by lactate dehydrogenase measurement and propidium iodide staining). It has been shown that combination of TLR2 and TLR4 blocking antibodies suppressed the cytotoxic and antiangiogenic effects on endothelial cells [39]. We have also found the macrophages from double TLR2 and TLR4 KO mice had dramatically 
reduced IL-1ß release induced by inflammasome protocol after the exposure to individual histones compared to single KO of TLR2 or TLR4 [23].

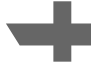

4. Molecular Basis of Cardiac Dysfunction Developing during Polymicrobial Sepsis (Figure 3)

Figure 3 describes how infectious sepsis activates a series of signaling pathways that have detrimental effects on cardiac function in mice. Initially, the mitogen-activated protein kinase (MAPK), especially p38, and Akt signaling pathways are activated, followed by increased plasma levels of various cytokines, chemokines and extracellular histones. The results of these events caused significant dysfunction of CMs. The basis for defects in $\mathrm{CM}$ function was linked to p38 activation, since a water soluble inhibitor of p38 prevented development of sepsis-induced heart dysfunction, as defined by ECHO-Doppler parameters [40]. Reasons for septic cardiomyopathy could be traced to defects in $\mathrm{Na}^{+} / \mathrm{K}^{+}$-ATPase, which (2) is critical for effective action potentials in CMs and in other cell types. Defects in SERCA2 and NCX led to diastolic buildup of $\left[\mathrm{Ca}^{2+}\right] \mathrm{i}$ in $\mathrm{CMs}$ in a manner that was associated with the inability to clear cytosolic $\left[\mathrm{Ca}^{2+}\right] \mathrm{i}$ in $\mathrm{CMs}$ during diastole $[8,9,34]$. Such events caused substantial dysfunction and apoptosis of CMs. We believe these events likely occurred in other organs (brain, liver, lungs, etc.), resulting in multiorgan dysfunction in sepsis. Based on this information, blocking p38 activation might be a strategy to prevent cardiac dysfunction developing in sepsis in humans.

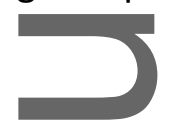

5. Conclusions

The data in Figures 1, 2 and 3 emphasize the appearance of complement activation products and histones during sepsis, leading to cardiac dysfunction. Since $\mathrm{C} 5 \mathrm{a}$ is such a key 
factor in many induced defects developing in septic cardiomyopathy, in vivo blockade of either $\mathrm{C} 5 \mathrm{a}$ or $\mathrm{C} 5 \mathrm{aRs}$ in septic mice would be an obvious potential therapeutic strategy. Such 12 inhibitors are not currently available but are under development. In severe sepsis in humans, most events leading to lethality occur during the first 3-5 days after onset of sepsis, especially in elderly septic patients. Therapeutic application of C5a or signaling pathway inhibitors would only be for a limited period of time (3-5 days). Currently, several pharmaceutical companies are developing small molecular weight compounds that block $\mathrm{C5a}$ or $\mathrm{C5}$, although clinical trials have not yet been done in order to assess safety and efficacy of these compounds. In terms of blockade of C5b-9, there do not yet appear to be any FDA-approved drugs, except perhaps antibody to C5, that result in blockade of generation of $\mathbf{C 5}$ b-9. However, the use of mAb to human $\mathrm{C5}$ (eculizumab), which should block generation of $\mathrm{C} 5 \mathrm{a}$ and $\mathrm{C} 5 \mathrm{~b}-9$, is also associated with predilection to development of (n) meningococcal meningitis. In some diseases affecting the complement system, such as paroxysmal nocturnal hemoglobinuria $(\mathrm{PNH})$ and atypical hemolytic uremic syndrome (aHUS), clinical trials showed that eculizumab is effective and safe [41]. However, in the setting of infectious sepsis associated with bacteremia, use of anti-C5 would likely face a very high barrier for FDA approval that would require very expensive clinical trials on the safety of such an intervention. In the short term, it seems unlikely that FDA approval would be granted. Development of small molecule inhibitors than block the activation epitope of C9 would be an attractive strategy to prevent the biological activity of C5b-9. There are currently mAbs that block the epitope of activated C9, but this mAb has not been used in humans. Targeting IL-1 produced by the activated NLRP3 inflammasome has already been tried unsuccessfully in septic humans using a compound IL-1 (IL-1r antagonist, IL-1ra 
[anakinra]) $[42,43]$. One study in septic mice applying combination therapy targeting IL-1 and IL-18 showed promising data [44]. Vanden Berghe et al, using CLP or LPS-induced endotoxemia in mice, showed that only the combined neutralization of IL-1ra and anti-IL-18 conferred complete protection against endotoxin-induced lethality in the mice. They also found similar results after applying the mice genetically deficient for both IL-1 $\beta$ and IL-18 [44]. Although clinical trials using these combination therapies would be needed to confirm the mice data, the results of the failed clinical trials using blockade of IL-1 have discouraged additional clinical trials featuring blockade of IL-1RA. It is important to suggest that, beyond sepsis, blocking $\mathrm{C} 5 \mathrm{a}$ or its receptors or C5b-9 might have relevance in many other situations in humans, such as acute cardiac ischemia, acute lung injury, autoimmune diseases (e.g. rheumatoid arthritis, systemic lupus erythematosus) and early allograft rejection.

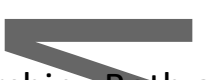

Authorship Both authors contributed equally to this Mini-Review.

Acknowledgments These studies were supported by the Godfrey D. Stobbe Endowment, Department of Pathology, University of Michigan Medical School.

Disclosures The authors declare no conflicts of interest and no relevant financial disclosures.

\section{$\underline{\text { References }}$}

1. Wang, H. E., Shapiro, N. I., Angus, D. C., Yealy, D. M. (2007) National estimates of severe sepsis in United States emergency departments. Crit Care Med 35, 1928-36.

2. Rivers, E., Nguyen, B., Havstad, S., Ressler, J., Muzzin, A., Knoblich, B., Peterson, E., Tomlanovich, M., Early Goal-Directed Therapy Collaborative, G. (2001) Early goal-directed therapy in the treatment of severe sepsis and septic shock. N Engl J Med 345, 1368-77. 
3. Chun, K., Syndergaard, C., Damas, C., Trubey, R., Mukindaraj, A., Qian, S., Jin, X., Breslow, S., Niemz, A. (2015) Sepsis Pathogen Identification. J Lab Autom 20, 539-61.

4. Iskander, K. N., Osuchowski, M. F., Stearns-Kurosawa, D. J., Kurosawa, S., Stepien, D., Valentine, C., Remick, D. G. (2013) Sepsis: multiple abnormalities, heterogeneous responses, and evolving understanding. Physiol Rev 93, 1247-88.

5. Dellinger, R. P., Levy, M. M., Carlet, J. M., Bion, J., Parker, M. M., Jaeschke, R., Reinhart, K., Angus, D. C., Brun-Buisson, C., Beale, R., Calandra, T., Dhainaut, J. F., Gerlach, H., Harvey, M., Marini, J. J., Marshall, J., Ranieri, M., Ramsay, G., Sevransky, J., Thompson, B. T., Townsend, S., Vender, J. S., Zimmerman, J. L., Vincent, J. L. (2008) Surviving Sepsis Campaign:

international guidelines for management of severe sepsis and septic shock: 2008. Intensive Care Med 34, 17-60.

6. Seok, J., Warren, H. S., Cuenca, A. G., Mindrinos, M. N., Baker, H. V., Xu, W., Richards, D. R., McDonald-Smith, G. P., Gao, H., Hennessy, L., Finnerty, C. C., Lopez, C. M., Honari, S., Moore, E. E., Minei, J. P., Cuschieri, J., Bankey, P. E., Johnson, J. L., Sperry, J., Nathens, A. B., Billiar, T. R., West, M. A., Jeschke, M. G., Klein, M. B., Gamelli, R. L., Gibran, N. S., Brownstein, B. H., Miller-Graziano, C., Calvano, S. E., Mason, P. H., Cobb, J. P., Rahme, L. G., Lowry, S. F., Maier, R. V., Moldawer, L. L., Herndon, D. N., Davis, R. W., Xiao, W., Tompkins, R. G., Inflammation, Host Response to Injury, L. S. C. R. P. (2013) Genomic responses in mouse models poorly mimic human inflammatory diseases. Proc Natl Acad Sci U S A 110, 3507-12.

7. Takao, K. and Miyakawa, T. (2015) Genomic responses in mouse models greatly mimic human inflammatory diseases. Proc Natl Acad Sci U S A 112, 1167-72.

8. Fattahi, F., Frydrych, L. M., Bian, G., Kalbitz, M., Herron, T. J., Malan, E. A., Delano, M. J., Ward, P. A. (2018) Role of complement C5a and histones in septic cardiomyopathy. Mol Immunol 102, 32-41.

9. Kalbitz, M., Fattahi, F., Herron, T. J., Grailer, J. J., Jajou, L., Lu, H., Huber-Lang, M., Zetoune, F. S., Sarma, J. V., Day, S. M., Russell, M. W., Jalife, J., Ward, P. A. (2016) Complement Destabilizes Cardiomyocyte Function In Vivo after Polymicrobial Sepsis and In Vitro. J Immunol 197, 2353-61.

10. Rittirsch, D., Hoesel, L. M., Ward, P. A. (2007) The disconnect between animal models of sepsis and human sepsis. J Leukoc Biol 81, 137-43.

11. Deitch, E. A. (1998) Animal models of sepsis and shock: a review and lessons learned. Shock 9, 1-11.

12. Buras, J. A., Holzmann, B., Sitkovsky, M. (2005) Animal models of sepsis: setting the stage. Nat Rev Drug Discov 4, 854-65.

13. Remick, D. G., Newcomb, D. E., Bolgos, G. L., Call, D. R. (2000) Comparison of the mortality and inflammatory response of two models of sepsis: lipopolysaccharide vs. cecal ligation and puncture. Shock 13, 110-6.

14. Wichterman, K. A., Baue, A. E., Chaudry, I. H. (1980) Sepsis and septic shock--a review of laboratorymodels and a proposal. J Surg Res 29, 189-201.

15. Rittirsch, D., Huber-Lang, M. S., Flierl, M. A., Ward, P. A. (2009) Immunodesign of experimental sepsis by cecal ligation and puncture. Nat Protoc 4, 31-6.

16. Cuenca, A. G., Delano, M. J., Kelly-Scumpia, K. M., Moldawer, L. L., Efron, P. A. (2010) Cecal ligation and puncture. Curr Protoc Immunol Chapter 19, Unit 1913.

17. Rittirsch, D, Flierl, M. A., Ward, P. A. (2008) Harmful molecular mechanisms in sepsis. Nat Rev Immunol 8, 776-87.

18. Ward, P. A. (2004) The dark side of C5a in sepsis. Nat Rev Immunol 4, 133-42.

19. Guo, R. F., Riedemann, N. C., Ward, P. A. (2004) Role of C5a-C5aR interaction in sepsis. Shock 21, 1-7. 
20. Fattahi, F., Grailer, J. J., Jajou, L., Zetoune, F. S., Andjelkovic, A. V., Ward, P. A. (2015) Organ distribution of histones after intravenous infusion of FITC histones or after sepsis. Immunol Res 61, 177-86.

21. Bosmann, M., Grailer, J. J., Ruemmler, R., Russkamp, N. F., Zetoune, F. S., Sarma, J. V., Standiford, T. J., Ward, P. A. (2013) Extracellular histones are essential effectors of C5aR- and C5L2-mediated tissue damage and inflammation in acute lung injury. FASEB J 27, 5010-21.

22. Grailer, J J., Canning, B. A., Kalbitz, M., Haggadone, M. D., Dhond, R. M., Andjelkovic, A. V., Zetoune, F. S., Ward, P. A. (2014) Critical role for the NLRP3 inflammasome during acute lung injury. J Immunol 192, 5974-83.

23. Fattahi, F., Grailer, J. J., Lu, H., Dick, R. S., Parlett, M., Zetoune, F. S., Nunez, G., Ward, P. A. (2017) Selective Biological Responses of Phagocytes and Lungs to Purified Histones. J Innate Immun 9, 300-317.

24. Suresh, R., Chandrasekaran, P., Sutterwala, F. S., Mosser, D. M. (2016) Complementmediated 'bystander' damage initiates host NLRP3 inflammasome activation. J Cell Sci 129, 1928-39.

25. Heesterbeek, D. A. C., Angelier, M. L., Harrison, R. A., Rooijakkers, S. H. M. (2018) Complement and Bacterial Infections: From Molecular Mechanisms to Therapeutic Applications. J Innate Immun 10, 455-464.

26. Nguyen, G. T., Green, E. R., Mecsas, J. (2017) Neutrophils to the ROScue: Mechanisms of NADPH Oxidase Activation and Bacterial Resistance. Front Cell Infect Microbiol 7, 373.

27. Kobayashi, S. D., Malachowa, N., DeLeo, F. R. (2018) Neutrophils and Bacterial Immune Evasion. J Innate Immun 10, 432-441.

28. Flannagan, R. S., Heit, B., Heinrichs, D. E. (2015) Antimicrobial Mechanisms of Macrophages and the Immune Evasion Strategies of Staphylococcus aureus. Pathogens 4, 826-68.

29. Triantafilou, K., Hughes, T. R., Triantafilou, M., Morgan, B. P. (2013) The complement membrane attack complex triggers intracellular Ca2+ fluxes leading to NLRP3 inflammasome activation. J Cell Sci 126, 2903-13.

30. Xu, J., Zhang, X., Monestier, M., Esmon, N. L., Esmon, C. T. (2011) Extracellular histones are mediators of death through TLR2 and TLR4 in mouse fatal liver injury. J Immunol 187, 262631.

31. Semeraro, F., Ammollo, C. T., Morrissey, J. H., Dale, G. L., Friese, P., Esmon, N. L., Esmon, C. T. (2011) Extracellular histones promote thrombin generation through platelet-dependent mechanisms: involvement of platelet TLR2 and TLR4. Blood 118, 1952-61.

32. Allam, R., Scherbaum, C. R., Darisipudi, M. N., Mulay, S. R., Hagele, H., Lichtnekert, J., Hagemann, J. H., Rupanagudi, K. V., Ryu, M., Schwarzenberger, C., Hohenstein, B., Hugo, C., Uhl, B., Reichel, C. A., Krombach, F., Monestier, M., Liapis, H., Moreth, K., Schaefer, L., Anders, H. J. (2012) Histones from dying renal cells aggravate kidney injury via TLR2 and TLR4. J Am Soc Nephrol 23, 1375-88.

33. Darwiche, S. S., Ruan, X., Hoffman, M. K., Zettel, K. R., Tracy, A. P., Schroeder, L. M., Cai, C., Hoffman, R. A., Scott, M. J., Pape, H. C., Billiar, T. R. (2013) Selective roles for toll-like receptors 2,4 , and 9 in systemic inflammation and immune dysfunction following peripheral tissue injury. J Trauma Acute Care Surg 74, 1454-61.

34. Kalbitz, M., Grailer, J. J., Fattahi, F., Jajou, L., Herron, T. J., Campbell, K. F., Zetoune, F. S., Bosmann, M., Sarma, J. V., Huber-Lang, M., Gebhard, F., Loaiza, R., Valdivia, H. H., Jalife, J., Russell, M. W., Ward, P. A. (2015) Role of extracellular histones in the cardiomyopathy of sepsis. FASEB J 29, 2185-93.

35. Kalbitz, M., Fattahi, F., Grailer, J. J., Jajou, L., Malan, E. A., Zetoune, F. S., Huber-Lang, M., Russell, M. W., Ward, P. A. (2016) Complement-induced activation of the cardiac NLRP3 inflammasome in sepsis. FASEB J 30, 3997-4006. 
36. Fuchs, T. A., Brill, A., Duerschmied, D., Schatzberg, D., Monestier, M., Myers, D. D., Jr., Wrobleski, S. K., Wakefield, T. W., Hartwig, J. H., Wagner, D. D. (2010) Extracellular DNA traps promote thrombosis. Proc Natl Acad Sci U S A 107, 15880-5.

37. Fattahi, F., Russell, M. W., Malan, E. A., Parlett, M., Abe, E., Zetoune, F. S., Ward, P. A. (2018) Harmful Roles of TLR3 and TLR9 in Cardiac Dysfunction Developing during Polymicrobial Sepsis. Biomed Res Int 2018, 4302726.

38. Ekaney, M.L., Otto, G. P., Sossdorf, M., Sponholz, C., Boehringer, M., Loesche, W., Rittirsch, D., Wilharm, A., Kurzai, O., Bauer, M., Claus, R. A. (2014) Impact of plasma histones in human sepsis and their contribution to cellular injury and inflammation. Crit Care 18, 543.

39. Mena, H. A., Carestia, A., Scotti, L., Parborell, F., Schattner, M., Negrotto, S. (2016) Extracellular histones reduce survival and angiogenic responses of late outgrowth progenitor and mature endothelial cells. J Thromb Haemost 14, 397-410.

40. Fattahi, F., Kalbitz, M., Malan, E. A., Abe, E., Jajou, L., Huber-Lang, M. S., Bosmann, M., Russell, M. W., Zetoune, F. S., Ward, P. A. (2017) Complement-induced activation of MAPKs and Akt during sepsis: role in cardiac dysfunction. FASEB J 31, 4129-4139.

41. Wong, E.K. and Kavanagh, D. (2015) Anticomplement C5 therapy with eculizumab for the treatment of paroxysmal nocturnal hemoglobinuria and atypical hemolytic uremic syndrome, Transl Res 165, 306-20.

42. Fisher, C. J., Jr., Slotman, G. J., Opal, S. M., Pribble, J. P., Bone, R. C., Emmanuel, G., Ng, D., Bloedow, D. C., Catalano, M. A., Group, I.-R. S. S. S. (1994) Initial evaluation of human recombinant interleukin-1 receptor antagonist in the treatment of sepsis syndrome: a randomized, open-label, placebo-controlled multicenter trial. Crit Care Med 22, 12-21.

43. Fisher, C. J., Jr., Dhainaut, J. F., Opal, S. M., Pribble, J. P., Balk, R. A., Slotman, G. J., Iberti, T. J., Rackow, E. C., Shapiro, M. J., Greenman, R. L., et al. (1994) Recombinant human interleukin 1 receptor antagonist in the treatment of patients with sepsis syndrome. Results from a randomized, double-blind, placebo-controlled trial. Phase III rhIL-1ra Sepsis Syndrome Study Group. JAMA 271, 1836-43.

44. Vanden Berghe, T., Demon, D., Bogaert, P., Vandendriessche, B., Goethals, A., Depuydt, B., Vuylsteke, M., Roelandt, R., Van Wonterghem, E., Vandenbroecke, J., Choi, S. M., Meyer, E., Krautwald, S., Declercq, W., Takahashi, N., Cauwels, A., Vandenabeele, P. (2014) Simultaneous targeting of IL-1 and IL-18 is required for protection against inflammatory and septic shock. Am J Respir Crit Care Med 189, 282-91.

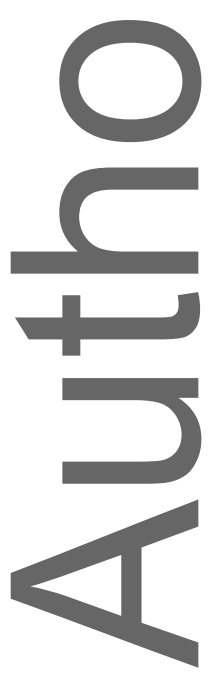




\section{Figure Legends}

Figure 1. Sequence of events developing during infectious sepsis and the important role of complement activation, which results in generation of two major products, $\mathrm{C} 5 \mathrm{a}$ and $\mathrm{C} 5 \mathrm{~b}-\mathrm{9}$ (membrane attack complex). C5a activates polymorphonuclear leukocytes (neutrophils) that form NETS which release extracellular histones and proinflammatory peptides. C5b-9 activates the NLRP3 inflammasome, leading to release of two potent cytokines, IL-1 $\beta$ and IL-

18.

Role of Complement in Polymicrobial Sepsis

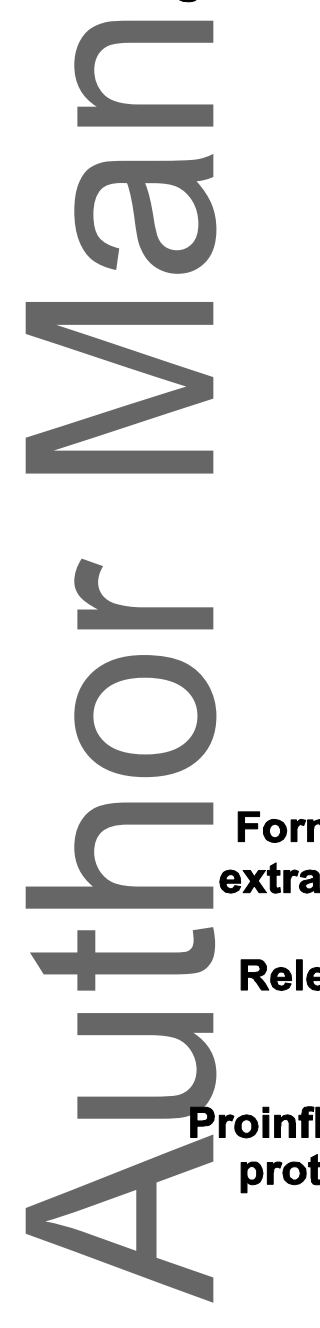

\section{Figure 1}

PMN activation C5aR1, C5aR2

\section{Complement activation}

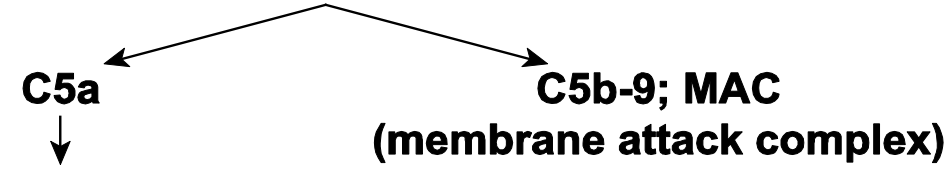

$\downarrow$

Formation of neutrophil extracellular traps (NETs)

Release of extracellular histones

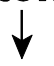
prothrombic responses

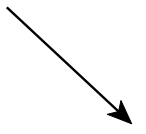

Cell and multiorgan damage
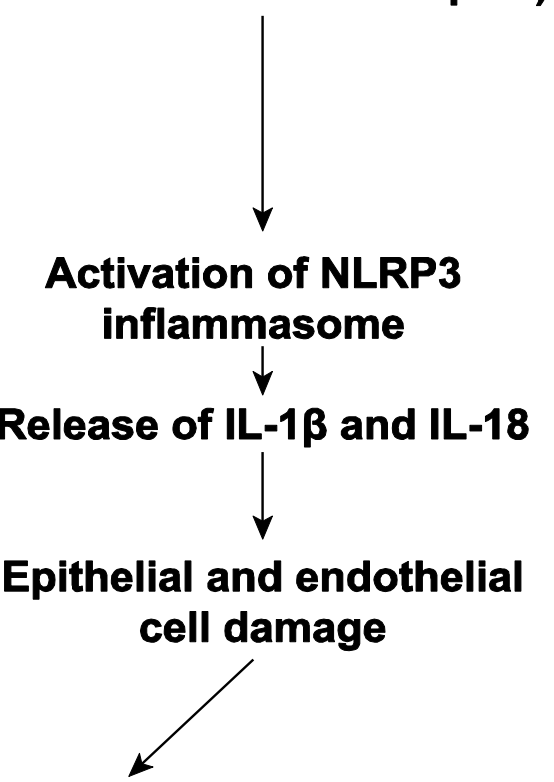
Figure 2. Infectious sepsis leads to the appearance of extracellular histones which interact with TLR2 and TLR4. This results in activation of the clotting system with thrombus formation, activation of neutrophils and macrophages that trigger a series of proinflammatory outcomes, together with ensuing cell damage and apoptosis.

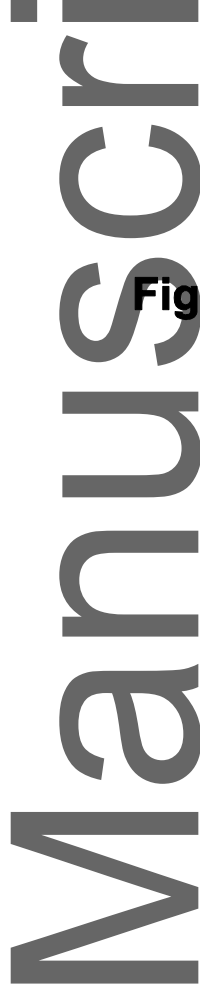

Mechanisms of Histone-Induced Cell Damage in Sepsis

gure 2
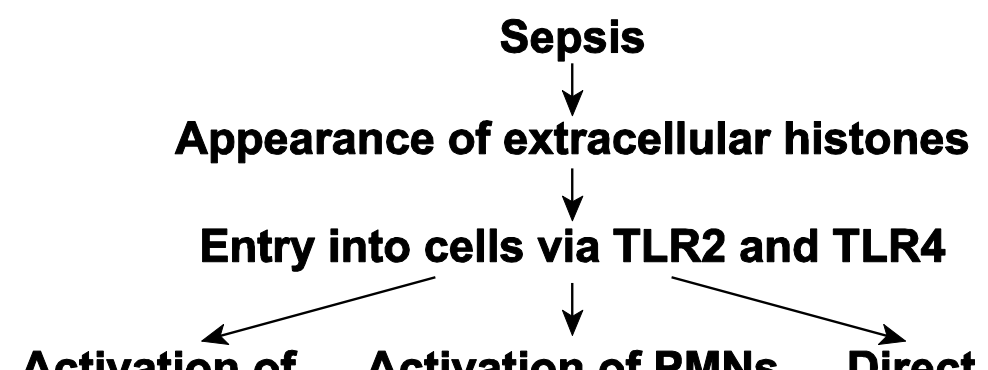

Activation of Activation of PMNs Direct cell damage platelets<smiles>[AlH]</smiles>

Activation of and macrophages and apoptosis

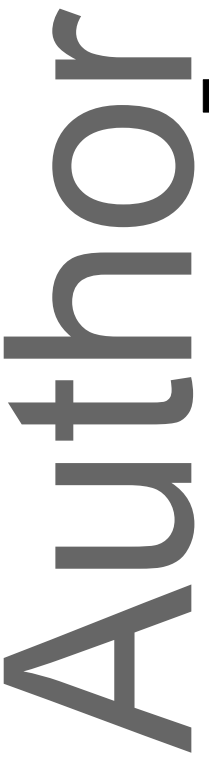
prothrombotic pathways

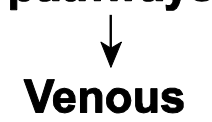
thrombosis

Cell dysfunction and apoptosis 
Figure 3. Events in infectious sepsis that cause the cardiomyopathy of sepsis, which is defined as contractile and relaxation defects in cardiomyocytes (CMs). The outcomes can be traced in MAPK (p38) and Akt activation in CMs, leading to cardiac dysfunction. These defects are associated with defective action potentials (reduced $\mathrm{Na}^{+} / \mathrm{K}^{+}$-ATPase) in CMs, together with reduced activity of $\left[\mathrm{Ca}^{2+}\right]$ i regulatory proteins, SERCA2 and NCX.

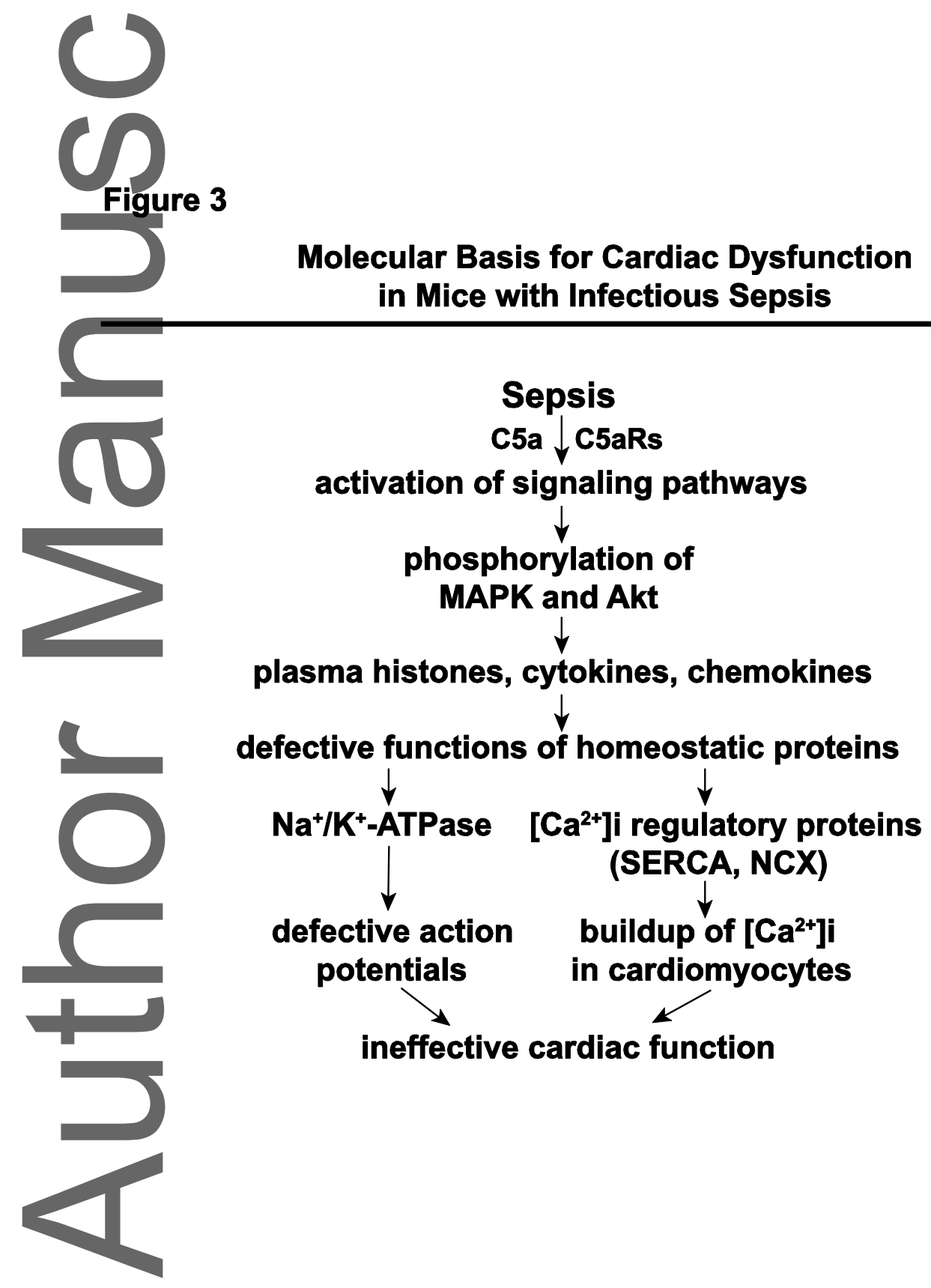

